\title{
Fontes e níveis da salinidade da água na formação de mudas de mamoeiro cv. sunrise solo
}

\section{Sources and levels of salinity of water on seedlings of papaya tree cv. sunrise solo}

\author{
Lourival Ferreira Cavalcante ${ }^{1}$; Jorge Chaves Cordeiro' ${ }^{2}$, José Adeilson Medeiros \\ Nascimento $^{3 *}$; Ítalo Herbert Lucena Cavalcante ${ }^{4}$; Thiago Jardelino Dias ${ }^{3}$
}

\begin{abstract}
Resumo
No período, de janeiro a março de 2005 , foi desenvolvido um experimento em abrigo telado para avaliar o efeito de fontes e níveis de salinidade sobre a emergência e desenvolvimento inicial de plântulas de mamão Havaí cv. Sunrise Solo. Os tratamentos foram distribuídos em delineamento inteiramente casualizado, em esquema fatorial $3 \times 5$, correspondente a três fontes (água salina de barragem (AS), água concentrada em cloreto de sódio $(\mathrm{NaCl})$ e água rica em sulfato de sódio $\left(\mathrm{Na}_{2} \mathrm{SO}_{4}\right)$ e cinco níveis de salinidade $\left(0,4 ; 2,0 ; 4,0 ; 6,0\right.$ e 8,0 dS m$\left.~^{-1}\right)$ em cinco repetições. Aos 60 dias após a emergência foram avaliadas as seguintes variáveis: Condutividade elétrica do extrato de saturação do solo (CEes), \% de emergência de sementes, altura de plantas, diâmetro caulinar na altura do colo e biomassa seca de parte aérea e raízes. A CEes do substrato foi elevada, independentemente da fonte utilizada, com maior expressividade para a água de barragem, e as variáveis de crescimento vegetativo avaliadas foram inibidas, independentemente da fonte utilizada, com o incremento da salinidade da água de irrigação. Palavras-chave: Carica papaya L, propagação, água de barragem, cloreto de sódio, sulfato de sódio
\end{abstract}

\begin{abstract}
From January to March of 2005 one experiment was developed in a screen house to evaluate the effect of sources and levels of water salinity on emergence and initial development of papaya seedlings cv. Sunrise Solo. A completely randomized experimental design was used and treatments were distributed in a factorial arrangement $3 \times 5$, corresponding to three sources (dam water, water salinized with sodium and water salinized with sodium sulfate) and five water saline levels $\left(0.4 ; 2.0 ; 4.0 ; 6.0\right.$ e $\left.8.0 \mathrm{dS}^{-1} \mathrm{~m}^{-1}\right)$ and five replications. At 60 days after seedling emergence the following variables were evaluated: soil electrical conductivity, seedling emergence, plant height, stem diameter and dry mass of shoots and roots. The soil electrical conductivity increased independently of salt source, with more expressiveness for dam water, and all evaluated variables of plant growth were inhibited with water salinity increase. Key words: Carica papaya L, propagation, dam water, sodium chloride, sodium sulfate
\end{abstract}

\footnotetext{
${ }^{1}$ Professor do Departamento de Solos e Engenharia Rural, CCA/UFPB, Areia, PB, CEP: 58397-000, pesquisador do INCTS. E-mail: al.lofeca@cca.ufpb.br

${ }^{2}$ Professor do Departamento de Metodologia da educação, CE/UFPB, João Pessoa, CEP: 58910-000. E-mail: jbakana@ibest.com. br

${ }^{3}$ Aluno de Doutorado do Curso de Pós-Graduação em Agronomia do Centro de Ciências Agrárias da Universidade Estadual da Paraíba, Areia, PB, CEP: 58397-000.E-mail: adeilsonagr@bol.com.br; tjardelino@hotmail.com

${ }^{4}$ Professor do Departamento de Engenharias, Campus Prof ${ }^{a}$. Cinobelina Elvas, CPCE, Universidade Federal do Piauí, UFPI. BR 135, CEP 64900-000 Bom Jesus, PI. E-mail: italohlc@ufpi.edu.br

* Autor para correspondência
} 


\section{Introdução}

O Brasil é o maior produtor de mamão (Carica papaya L.) do mundo, fruta bastante apreciada tanto pela qualidade nutricional quanto por suas características organolépticas, ganhando atenção especial por parte dos produtores e redes de comercialização (GALVÃO et al., 2007). O nordeste brasileiro contribui expressivamente com a produção nacional de mamão, sendo os estados da Bahia e Espírito Santo os principais produtores e atualmente o Rio Grande do Norte, formando assim o grupo dos maiores exportadores do país (Anuário Brasileiro de Fruticultura, 2010). No entanto, considerando as condições edafoclimáticas de boa parte das terras do semi-árido nordestino e a irregularidade pluviométrica dessas regiões, seu cultivo só é possível, de forma economicamente viável, sob condições de irrigação.

Apesar da expressividade da irrigação na produção de frutíferas e de alimentos, em geral, nas regiões semiáridas, onde a evapotranspiração supera a pluviosidade a salinidade do solo e da água de irrigação se constitui num grande obstáculo ao sistema de produção (CAVALCANTE et al., 2005; FREIRE et al., 2010). O mamoeiro é considerado moderadamente tolerante à salinidade do solo, isso significa que suporta níveis de condutividade elétrica do extrato de saturação do solo entre 3 e $6 \mathrm{dS} \mathrm{m}^{-1}$ sem inibição do crescimento e da sua capacidade produtiva (AYERS; WESTCOT, 1999). Apesar da maior tolerância aos sais, em relação às frutíferas como bananeira, goiabeira e gravioleira que são mais sensíveis, o cultivo do mamoeiro irrigado nas áreas semiáridas brasileiras tem provocado aumento da concentração salina no solo tanto em função da elevada temperatura do ar como pelo conteúdo salino elevado das águas. Essa inconveniência resulta na inibição do crescimento em altura, diâmetro caule, área foliar e acúmulo de biomassa e de produção das frutíferas, em geral, inclusive o mamoeiro (CAVALCANTE et al., 2006).
Informações a respeito da produção de frutíferas irrigadas com águas salinas, oriundas de mananciais hídricos de superfície ou poços artesianos, ainda são pouco freqüentes na literatura. Dessa forma, Gheyi et al. (2006) e Nascimento (2010) produziram bananeira e maracujazeiro amarelo, que são culturas sensíveis à salinidade (AYERS; WESTCOT, 1999), irrigadas respectivamente com águas de níveis salinos variando de 0,2 a $4,0 \mathrm{dS} \mathrm{m}^{-1}$. São escassos também artigos referentes aos efeitos da salinidade da água rica em $\mathrm{NaCl}$ e ou $\mathrm{Na}_{2} \mathrm{SO}_{4}$ na germinação, crescimento inicial e produção de biomassa do mamoeiro. Nesse sentido, Santos (2000) observou que a irrigação com água salina concentrada em cloreto de sódio inibiu a germinação de sementes do mamoeiro na região semiárida do Rio Grande do Norte.

O cloreto de sódio contido na água de irrigação prejudica o desenvolvimento inicial da grande maioria das frutíferas como pinheira (LIMA; CAVALCANTE; FEITOSA FILHO, 2001), goiabeira (TÁVORA; PEREIRA; HERNADEZ, 2001) e cajueiro anão precoce (ABREU et al., 2008). Ferreira, Távora e Hernandes (2001) avaliaram a distribuição de matéria seca de goiabeira submetida a estresse salino com $\mathrm{NaCl}$ e verificaram que houve uma sensível redução com o incremento da concentração de sais, atribuindo esse efeito ao aumento de $\mathrm{Na}$ e $\mathrm{Cl}$ nas raízes, caule e folhas das plantas. $\mathrm{O}$ incremento de $\mathrm{NaCl}$ na água de irrigação aumentou o conteúdo de $\mathrm{Na}$ e $\mathrm{Cl}$ nos tecidos vegetais de cajueiro anão, o que se refletiu na redução da produção de matéria seca de folhas e raízes como constatado por Morais et al. (2007).

O excesso de sais de sódio, além de trazer prejuízos às propriedades físicas e químicas do solo provoca à redução generalizada do crescimento das plantas cultivadas com sérios prejuízos à atividade agrícola. $\mathrm{O} \mathrm{Na}^{+}$aumenta a espessura da dupla camada iônica difusa, proporcionando a expansão das argilas e, conseqüentemente, reduzindo 
a porosidade e a permeabilidade (TÁVORA; PEREIRA; HERNADEZ, 2001). O acúmulo de $\mathrm{Na}$ e $\mathrm{Cl}$, de forma isolada ou associada, em tecidos vegetais resultam em toxicidade iônica devido a intensas mudanças nas relações $\mathrm{Na}^{+} / \mathrm{K}^{+}, \mathrm{Na}^{+} / \mathrm{Ca}^{+2} \mathrm{e}$ $\mathrm{Cl}^{-} / \mathrm{NO}^{-3}$, provocando quedas de rendimento e, até mesmo, morte das plantas (FERREIRA et al., 2005; FERREIRA-SILVA et al., 2008).

As informações sobre a formação de mudas e crescimento inicial do mamoeiro cultivado sob condições irrigadas são escassas nas condições do semi-árido nordestino. Considerando a importância econômica do mamoeiro para a economia brasileira e o aumento significativo das áreas plantadas irrigadas no Nordeste, o objetivo desse trabalho foi estudar o efeito de fontes e níveis de salinidade da água de irrigação sobre a emergência de plântulas e desenvolvimento vegetativo de mudas de mamão Havaí cv. Sunrise Solo até a idade adotada como ideal para o transplantio.

\section{Material e Métodos}

O trabalho foi conduzido em abrigo telado, no período de janeiro a março de 2005, no Setor de Fruticultura do Centro de Ciências Agrárias da Universidade Federal da Paraíba, Areia. O clima da região é tropical semi-úmido, com chuvas de março a julho ou até agosto e pluviosidade média anual de $1200 \mathrm{~mm}$. A temperatura média do ar é da ordem de $24{ }^{\circ} \mathrm{C}$ e a umidade relativa do ar varia de $75 \%$, em novembro, a $87 \%$ nos meses de junho e julho, respectivamente.

$\mathrm{O}$ experimento foi instalado em delineamento inteiramente casualizado, em arranjo fatorial $3 \times 5$, correspondente a três fontes de águas salinas (água salina de barragem (ASB), água concentrada em cloreto de sódio $(\mathrm{NaCl})$ e água rica em sulfato de sódio $\left.\left(\mathrm{Na}_{2} \mathrm{SO}_{4}\right)\right)$ em cinco níveis de condutividade

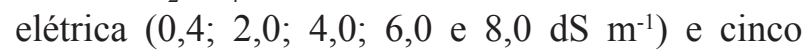
repetições. O substrato utilizado foi constituído de uma mistura de $50 \%$ de areia lavada, $25 \%$ de terra vegetal e $25 \%$ de esterco bovino curtido de relação C/N 18:1, com condutividade elétrica 2,0 dS m $\mathrm{d}^{-1} \mathrm{e}$ percentagem de sódio trocável 5,5\%. A formulação desse substrato é resultado de experimentos prévios avaliando as quantidades de areia lavada, terra vegetal e esterco que resultam em um melhor substrato para formação de mudas de mamoeiro, além disso, esse substrato é o mais comumente usado por produtores locais. Após preparado, o substrato foi acondicionado em bolsas de polietileno preto, com $20 \mathrm{~cm}$ de altura e $12 \mathrm{~cm}$ de diâmetro, onde foram semeadas quatro sementes de mamão Havaí cv. Sunrise Solo em cada unidade experimental.

Os níveis de salinidade da água de barragem (ASB) foram obtidos efetuando-se a diluição de água fortemente salina $\left(\mathrm{CEa}=9,3 \mathrm{dSm}^{-1}\right)$ em água não salina de condutividade elétrica $0,4 \mathrm{dS} \mathrm{m}^{-1}$ até obterem-se misturas com os valores de condutividade elétrica (CE) previamente estipulados. A água de barragem apresentava $\mathrm{pH}=8,6 ; \mathrm{Ca}^{2+}=15,1 \mathrm{mmol}_{\mathrm{c}}$ $\mathrm{L}^{-1} ; \mathrm{Mg}^{2+}=33,9 \mathrm{mmol}_{\mathrm{c}} \mathrm{L}^{-1} ; \mathrm{Na}^{+}=42,5 \mathrm{mmol}_{\mathrm{c}} \mathrm{L}^{-1} ; \mathrm{K}^{+}=$ $0,99 \mathrm{mmol}_{\mathrm{c}} \mathrm{L}^{-1} ; \mathrm{CE}=9,3 \mathrm{dS} \mathrm{m}{ }^{-1} ; \mathrm{RAS}=8,59(\mathrm{mmol}$ $\left.\mathrm{L}^{-1}\right)^{1 / 2}$, Classificada como $\mathrm{C}_{4} \mathrm{~S}_{3}$, o que significa água altamente salina $\left(\mathrm{C}_{4}\right)$ e com alto risco de sodificar o solo $\left(\mathrm{S}_{3}\right)$ (AYERS; WESTCOT, 1999). Para obtenção de cada valor de condutividade elétrica se mantém o volume constante da água fortemente salina e experimentalmente vai se adicionando água não salina até o valor da condutividade elétrica desejada, medida com condutivímetro. Dessa forma, se constata que a relação ASB:ANS não é unívoca, isto é, varia em função do teor salino de cada tipo de água. As águas salinas oriundas do $\mathrm{NaCl}$ e $\mathrm{Na}_{2} \mathrm{SO}_{4}$ foram preparadas usando a expressão: Cs $=0,01[(\mathrm{CEd}-0,4) / \mathrm{Gp}] \mathrm{x}$ Peq como procederam Lima, Cavalcante e Feitosa Filho (2001), em que: $\mathrm{Cs}=$ concentração de cada espécie iônica $\left(\mathrm{g} \mathrm{L}^{-1}\right)$; $\mathrm{CEd}=$ condutividade elétrica desejada; Peq= peso equivalente; $\mathrm{Gp}=$ grau de pureza de cada sal, respectivamente $97 \%$ para ambos (Tabela 1 ). 
Tabela 1. Volume de água destilada e concentração de cloreto e sulfato de sódio para a condutividade elétrica das águas utilizadas.

\begin{tabular}{|c|c|c|c|c|}
\hline $\mathrm{CE} 25^{\circ} \mathrm{C}$ & \multicolumn{2}{|c|}{ ASB:ANS } & $* \mathrm{NaCl}$ & $* * \mathrm{Na}_{2} \mathrm{SO}_{4}$ \\
\hline$\left(\mathrm{dS} \mathrm{m} \mathrm{m}^{-1}\right)$ & \multicolumn{2}{|c|}{---------- $\mathrm{dm}^{3}$----------- } & \multicolumn{2}{|c|}{ 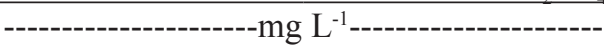 } \\
\hline 0,4 & 0 & 1,0 & 0 & 0 \\
\hline 2,0 & 1 & 8,0 & 0,96 & 1,17 \\
\hline 4,0 & 1 & 4,0 & 2,17 & 2,64 \\
\hline 6,0 & 1 & 2,0 & 3,38 & 4,09 \\
\hline 8,0 & 1 & 1,4 & 4,58 & 5,56 \\
\hline
\end{tabular}

$\mathrm{CE}=$ Condutividade elétrica; $\mathrm{ASB}=$ água salina de barragem; $\mathrm{ANS}=$ água não salina; * peso equivalente $=58,50 ; * *$ peso equivalente $=71$.

A irrigação foi realizada diariamente, com volume de cada fonte e valor de condutividade elétrica, baseado no processo de pesagem dos recipientes fornecendo-se diariamente o volume de cada tipo de água evapotranspirado, de modo a manter a umidade de cada substrato ao nível da capacidade de campo.

A partir do inicio da emergência das plântulas, diariamente foram efetuadas contagens das plântulas emergidas até a estabilização do processo conforme indicado em Brasil (1992) para análise de sementes de mamão. A altura foi medida semanalmente e o diâmetro do caule quinzenalmente, com auxilio de trena métrica e paquímetro, respectivamente. Quando as plantas irrigadas com água de menor condutividade elétrica atingiram a fase de transplantio, aos 60 dias após a emergência, efetuouse a coleta das plantas em três repetições das cinco totais. As plantas foram separadas em raiz e parte aérea e depois colocadas em estufa com circulação

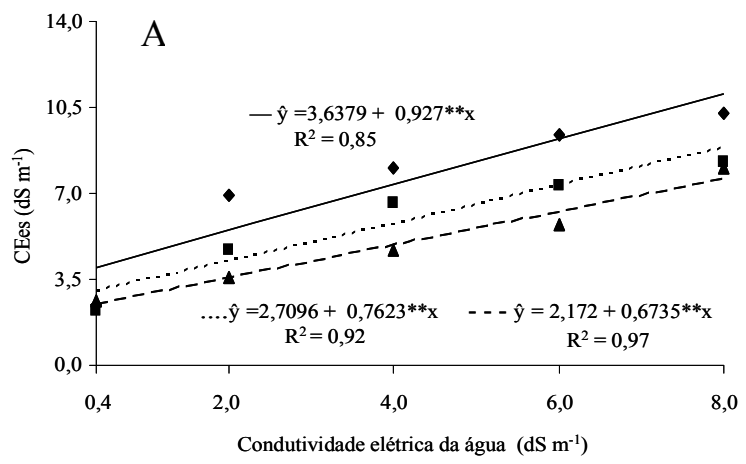

Figura 1. Condutividade elétrica do extrato de saturação (A) e emergência de plântulas (B) de mamoeiro Havaí, em função de níveis e fontes de sais da água irrigação ( - água salina de barragem, $\bullet . . . \mathrm{NaCl}, \boldsymbol{\Delta}$--- $\left.\mathrm{Na}_{2} \mathrm{SO}_{4}\right)$. de ar forçado a $65{ }^{\circ} \mathrm{C}$, até atingir peso constante. No mesmo dia da coleta das plantas, nas duas outras repetições, foram obtidas amostras de solo para avaliação do nível de salinidade do substrato, utilizando-se a metodologia descrita por Richards (1954).

Os resultados foram submetidos análise a de variância pelo teste "F" e por regressão polinomial.

\section{Resultados e Discussão}

De forma geral, todas as variáveis de desenvolvimento vegetativo, avaliadas, foram influenciadas significativamente pelo incremento dos níveis de salinidade, independentemente da fonte de sais encontrada na água de irrigação. A condutividade elétrica do extrato de saturação do solo (CEes) foi elevada pelo incremento de sais da água de irrigação, independentemente da fonte (Figura 1A).

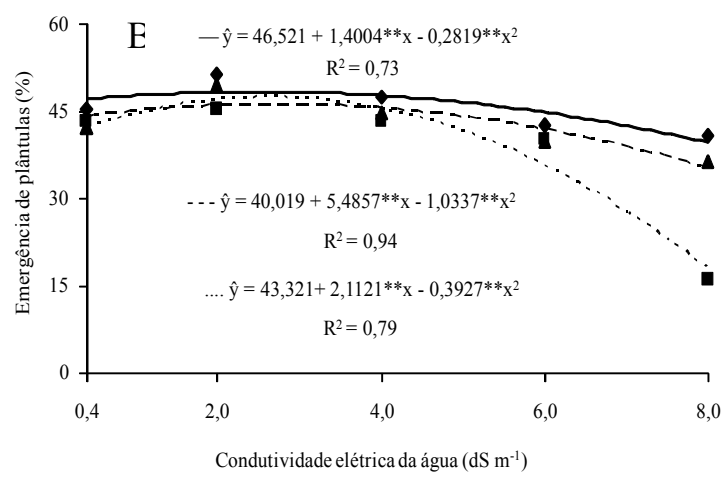


No entanto, a fonte de água que mais elevou a CEes do solo foi a água salina de barragem seguida da água concentrada em $\mathrm{NaCl}$. O caráter salino do substrato foi elevado de ligeiramente salino $(4,0$ $>$ CEes $>2,0 \mathrm{dS} \mathrm{m}^{-1}$ ), condição que compromete o desempenho das culturas sensíveis, para até fortemente salino, onde apenas as culturas mais tolerantes apresentam crescimento e rendimento satisfatórios (RICHARDS, 1954; EL-HENDAWY et al., 2005). A água salina de barragem no nível de $8,0 \mathrm{dS} \mathrm{m}^{-1}$ foi a que mais elevou a salinidade do substrato para incremento de até $75,7 \%$ em relação a água de menor salinidade $\left(0,4 \mathrm{dS} \mathrm{m}^{-1}\right)$, enquanto nos tratamentos com $\mathrm{NaCl}$ e $\mathrm{Na}_{2} \mathrm{SO}_{4}$ os aumentos foram 73,5 e 67,5\%, respectivamente, em termos absolutos a ordem da condutividade elétrica do extrato de saturação do solo foi: água salina de barragem $>\mathrm{NaCl}>\mathrm{Na}_{2} \mathrm{SO}_{4}$. Pelos resultados o complexo salino das águas de barragem elevou mais o teor salino do solo do que as fontes de salinidade especifica, como $\mathrm{NaCl}$ e $\mathrm{Na}_{2} \mathrm{SO}_{4}$. Lima, Cavalcante e Feitosa Filho (2001) avaliando o desenvolvimento inicial de gravioleira irrigada com água salina de barragem, água concentrada em $\mathrm{NaCl}$ e $\mathrm{MgCl}_{2}$ (1,0; 2,0; 3,0 e 10,0 dS m ${ }^{-1}$ ), também observaram que o substrato irrigado com água de barragem teve o conteúdo salino mais elevado em relação ao irrigado com água contendo as demais fontes de sais.

$\mathrm{O}$ incremento da $\mathrm{CEa}$ das águas inibiu a emergência de plântulas independentemente da fonte de sais utilizada na água de irrigação (Figura 1B). Apesar da água salina de barragem ter sido a fonte que mais salinizou o substrato foi a que proporcionou a maior emergência de plântulas e dentre as fontes de sais a que mais prejudicou a emergência foi a água concentrada em $\mathrm{NaCl}$. Percentualmente, os declínios da emergência das plântulas entre os valores das águas de maior e menor condutividade elétrica foram $10,13 \%$ para os tratamentos irrigados com águas salinas de barragem, $14,42 \%$ para os irrigados com água concentrada em $\mathrm{Na}_{2} \mathrm{SO}_{4}$ e $63,13 \%$ para as irrigadas com águas ricas em $\mathrm{NaCl}$. De forma geral, observa-se na Figura 1B que a germinação máxima obtida está em torno de $45 \%$ para a três fontes de salinidade e a partir do nível 4,0 dS m${ }^{-1}$ esta começa a decrescer, o que mostra que a germinação foi baixa, considerandose que Yamanishi et al. (2004) conseguiram valores de até $84,2 \%$ em substrato comercial (Plantmax + esterco + Osmocote) e irrigação com água não salina. No entanto os resultados estão compatíveis com os de Santos (2000) ao avaliar efeito de água rica em $\mathrm{NaCl}$, com condutividade elétrica variando de 0,5 a 4,5 dS m ${ }^{-1}$, na germinação de sementes do mamoeiro e com Lima, Cavalcante e Feitosa Filho (2001) em emergência de pinheira sob irrigação com águas salinas de barragem (ASB) e águas concentradas em $\mathrm{NaCl}$ e $\mathrm{Na}_{2} \mathrm{SO}_{4}(1,0 ; 2,0 ; 3,0$ e $10,0 \mathrm{dS} \mathrm{m}^{-1}$ ). Pela superioridade dos dados dos tratamentos irrigados com água de barragem em relação as demais fontes se percebe que durante o processo de emergência o mamoeiro Havai sofreu menos os efeitos degenerativos do complexo salino da água de barragem que da salinidade específica do sulfato e do cloreto de sódio. Comportamento semelhante foi verificado também por Cavalcante et al. (2001) ao constatarem que a irrigação com água de barragem, com níveis de condutividade elétrica de 0,$5 ; 1,0 ; 2,0 ; 3,0 ; 6,0$ e $9,0 \mathrm{dS} \mathrm{m}^{-1}$, foi a que mais salinizou e a que menos inibiu a emergência de plântulas de gravioleira A ação antagônica exercida pelo cálcio, magnésio e potássio sobre o sódio na água salina de barragem atenuam os efeitos depressivos do sódio durante o crescimento do eixo embrionário do mamoeiro em relação as águas ricas apenas no cátion sódio como nas águas ricas em $\mathrm{NaCl}$ e $\mathrm{Na}_{2} \mathrm{SO}_{4}$ (RICHARDS, 1954; TESTER; DAVENPORT, 2003; HU; SCHIMIDHALTER, 2004; PARIDA; DAS, 2005).

O crescimento em altura e o diâmetro do caule das plantas foram prejudicados com o aumento da condutividade elétrica da água de irrigação de qualquer das fontes de sais utilizadas (Figura 2), por onde se percebe que as plantas irrigadas com águas de $\mathrm{NaCl}$ na maior condutividade elétrica emergiram, porém não sobreviveram. Dentre as 

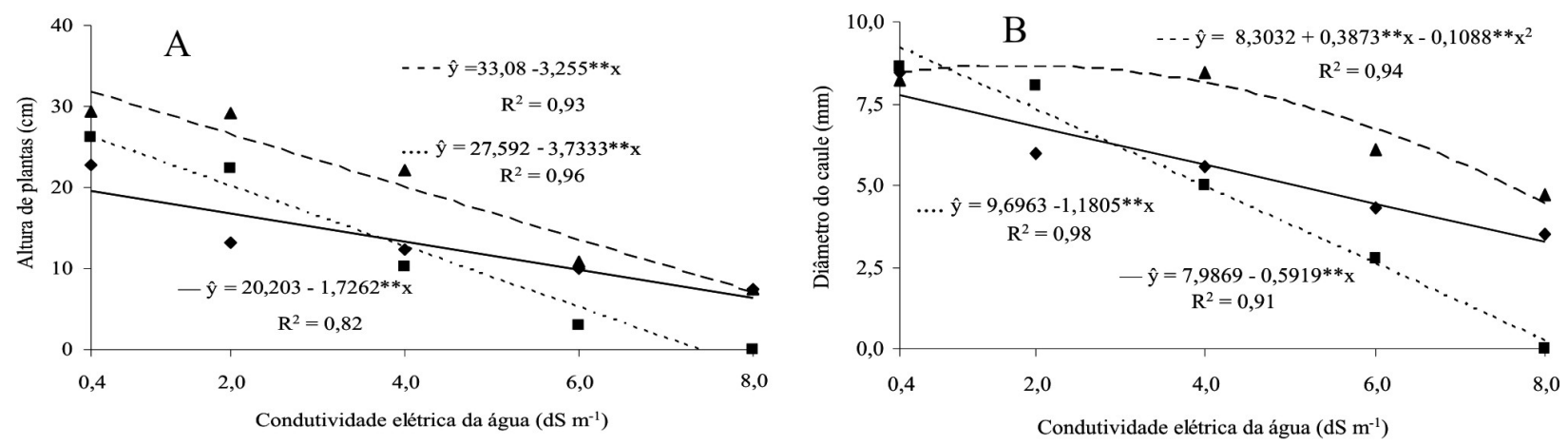

Figura 2. Altura (A) e diâmetro de caule (B) de plantas de mamoeiro Havaí, aos 60 dias após germinação, em função de níveis e fontes de sais da água de irrigação ( - água salina de barragem, $\boldsymbol{\bullet} . . . \mathrm{NaCl}, \boldsymbol{\Lambda}$--- $\mathrm{Na}_{2} \mathrm{SO}_{4}$ ).

fontes de sais a que menos inibiu o crescimento em altura e o diâmetro caulinar do mamoeiro foi a água rica em $\mathrm{Na}_{2} \mathrm{SO}_{4}$ seguida da água concentrada em $\mathrm{NaCl}$ e água de barragem.

Constata-se ordem diferente dos efeitos em comparação a emergência de plântulas. Na primeira variável a ordem dos efeitos na inibição foi na emergência $\mathrm{NaCl}>\mathrm{Na}_{2} \mathrm{SO}_{4}>$ água de barragem e na altura e diâmetro $\mathrm{NaCl}>$ água de barragem $>\mathrm{Na}_{2} \mathrm{SO}_{4}$. Essa situação reporta que o mamoeiro, assim como muitas outras plantas moderadamente tolerantes aos efeitos salinos (AYERS; WESTCOT, 1999) responde diferenciadamente à composição iônica da água de irrigação para um mesmo nível de condutividade elétrica. Tendências semelhantes foram apresentadas também pelo maracujazeiro amarelo que teve o crescimento diferenciado sob irrigação com águas salinas (CEa: 0, 2, 4, 6 e 8 dS m$\left.{ }^{-1}\right)$ apartir de $\mathrm{CaCl}, \mathrm{Ca}\left(\mathrm{NO}_{3}\right)_{2} \mathrm{NaCl}$ e $\mathrm{NaNO}_{3}$ (COSTA et al., 2005). Ao comparar os declínios da altura (Figura 2A) provocados pela água de maior $\mathrm{CEa}\left(8,0 \mathrm{dS} \mathrm{m}^{-1}\right)$ em relação a de menor $\mathrm{CEa}$ $\left(0,4 \mathrm{dS} \mathrm{m}^{-1}\right)$ percebe-se que o $\mathrm{NaCl}$ e a água de barragem foram responsáveis por uma redução de 100 e $74,4 \%$, respectivamente, enquanto que para a água concentrada em $\mathrm{Na}_{2} \mathrm{SO}_{4}$ as perdas foram de $67,1 \%$. Levando em consideração a redução de altura por cada aumento unitário de condutividade elétrica $(3,73,3,25$ e $1,72 \mathrm{~cm}$ para $\mathrm{NaCl}, \mathrm{ASB}$ e $\mathrm{Na}_{2} \mathrm{SO}_{4}$, respectivamente) a água com $\mathrm{Na}_{2} \mathrm{SO}_{4}$ foi a que menos comprometeu o crescimento em altura das plantas. Távora, Pereira e Hernadez. (2001) em goiabeira, Lima, Cavalcante e Feitosa Filho (2001) em pinheira e Abreu et al. (2008) em cajueiro anão precoce também observaram que irrigação com águas concentradas em $\mathrm{NaCl}$ afetou negativamente a altura de plantas. Ao considerar que a altura ideal de mudas para o transplantio do mamoeiro em campo aberto está entre 15 e $20 \mathrm{~cm}$, o que leva aproximadamente 40 dias após a germinação, quando a semente é de boa qualidade e é semeada em um substrato com boas qualidades físicas e químicas e sob irrigação com água sem restrição para a agricultura (OLIVEIRA; TRINDADE, 2000), as mudas irrigadas com água de condutividade elétrica a partir de $4,0 \mathrm{dS} \mathrm{m}^{-1}$ não apresentaram desenvolvimento satisfatório para cultivo. As plantas apresentaram maior crescimento quando irrigadas com água de menor salinidade $\left(0,4 \mathrm{dS} \mathrm{m}^{-1}\right)$. Como na altura, a ordem dos efeitos degenerativos dos sais ao diâmetro do caule foi: $\mathrm{NaCl}>$ água de barragem $>\mathrm{Na}_{2} \mathrm{SO}_{4}$ com perdas de 100,58 e $42 \%$, respectivamente, quando as plantas foram irrigadas com água de maior salinidade em relação a de menor salinidade (Figura 2B). Esses resultados estão em acordo com os apresentados por Lima, Cavalcante e Feitosa Filho. (2001) em pinheira, Cavalcante et al. (2001) em gravioleira sob irrigação com água salina. Esses decréscimos são provocados pela redução que o $\mathrm{NaCl}$ promove 
na absorção e transporte de elementos essenciais, resultando no desequilíbrio nutricional e em prejuízos ao desenvolvimento inicial das plantas (FERREIRA et al., 2001; EL-HENDAWY et al., 2005).

A biomassa seca das raízes e parte aérea foram expressivamente prejudicadas com aumento do teor salino das águas, expresso pela condutividade elétrica, independentemente da fonte (Figura $3)$, entretanto se verifica que nas raízes a ordem dos efeitos para os valores foi: $\mathrm{NaCl}>$ água de barragem $>\mathrm{Na}_{2} \mathrm{SO}_{4}$ e na parte aérea: Água de barragem $>\mathrm{Na}_{2} \mathrm{SO}>\mathrm{NaCl}$.

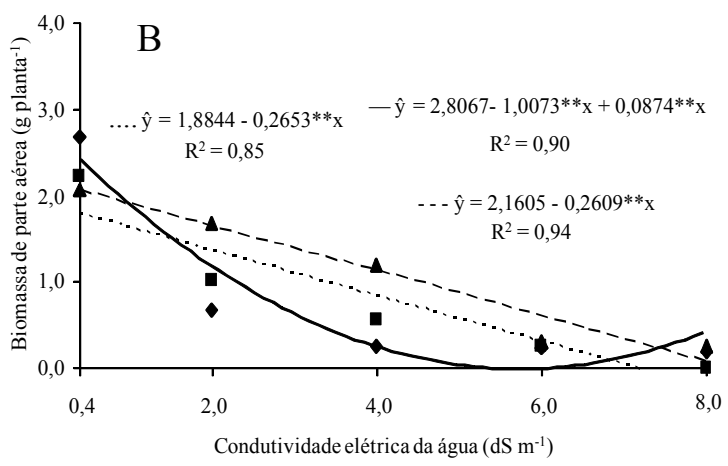

Figura 3. Biomassa de raiz (A) e parte aérea (B) de mamoeiro Havaí, aos 60 dias após a germinação, em função de níveis e fontes de sais da água irrigação $\left(-\right.$ água salina de barragem, $\square . . . \mathrm{NaCl}, \boldsymbol{\Lambda}$--- $\mathrm{Na}_{2} \mathrm{SO}_{4}$ ).

O cloreto de sódio e água de barragem foram as fontes que provocaram os menores valores absolutos de biomassa seca das raízes e parte aérea, mas com base nas expressões matemáticas, a exemplo do crescimento em altura, a perda de biomassa das raízes por cada aumento unitário de condutividade elétrica da água de irrigação foi menor nas plantas irrigadas com água de barragem, 0,033 g planta $^{-1}$, enquanto naquelas com águas concentradas em $\mathrm{NaCl}$ e em $\mathrm{Na}_{2} \mathrm{SO}_{4}$ as perdas por aumento unitário da salinidade das águas foram 0,079 e 0,0552 g planta $^{-1}$ (Figura 3A). Comparando e relacionando os valores de biomassa das raízes no maior nível de CEa em relação à água de menor $\mathrm{CEa}$, as perdas foram de 100,87 e $67,5 \%$ para as plantas irrigadas com águas concentradas em $\mathrm{NaCl}$, água de barragem e rica em $\mathrm{Na}_{2} \mathrm{SO}_{4}$ e ASB, respectivamente, evidenciando que embora a irrigação com água salina de barragem (ASB) tenha resultado em valores absolutos de biomassa seca de raízes menores que para a irrigação com água concentrada em $\mathrm{Na}_{2} \mathrm{SO}_{4}$, a redução de biomassa radicular no mesmo intervalo de CEa foi menor. Esses resultados estão em acordo com os obtidos por Ferreira-Silva et al. (2008) em cajueiro e com Abreu et al. (2008) em cajueiro anão irrigados com águas concentradas em $\mathrm{NaCl}$. O excesso de sódio na solução induz ao desequilíbrio nutricional promovendo toxicidade e no solo provoca a dispersão das argilas com conseqüente formação de camada de impedimento ao crescimento, respiração, expansão radicular, absorção de água e fixação de $\mathrm{CO}_{2}$ pela planta, resultando em uma menor taxa de crescimento e alocação de biomassa (TÁVORA; PEREIRA; HERNADEZ, 2001; SAQIB;AKHTAR; QURESHI, 2004; PARIDA; DAS, 2005).

A biomassa seca de parte aérea das plantas irrigadas com água de maior $\mathrm{CE}\left(8,0 \mathrm{dS} \mathrm{m}^{-1}\right)$ sofreu redução de 100, 93,2 e 87,8\% em relação as plantas submetidas às águas de $0,4 \mathrm{dS} \mathrm{m}^{-1}$ para $\mathrm{NaCl}$, $\mathrm{Na}_{2} \mathrm{SO}_{4}$ e água de barragem. Respectivamente (Figura 3B). Os resultados obtidos por Morais et al. (2007) em cajueiro anão mostram que o incremento 
na concentração de $\mathrm{NaCl}$ da água de irrigação promove um aumento de $\mathrm{Na}^{+}$e $\mathrm{Cl}^{-}$no tecido vegetal, reduzindo a produção de matéria seca de raízes e parte aérea. $\mathrm{O}$ cloreto de sódio afeta negativamente a síntese e a translocação de hormônios das raízes para parte aérea, indispensáveis ao metabolismo foliar, o que resulta na perda de área foliar e conseqüentemente na matéria seca da parte aérea das plantas (TÁVORA; PEREIRA; HERNADEZ, 2001; TAIZ; ZEIGER, 2006). Além dos efeitos osmóticos da salinidade, o excesso de $\mathrm{Na}$ e $\mathrm{Cl}$ nos tecidos vegetais resulta em toxicidade iônica devido ao aumento nas relações $\mathrm{Na}^{+} / \mathrm{K}^{+}, \mathrm{Na}^{+} / \mathrm{Ca}^{+2}$ e $\mathrm{Cl}^{-} / \mathrm{NO}^{-3}$ (SHI; ZHU, 2002; SAQIB, AKHTAR; QURESHI, 2004; FERREIRA-SILVA et al., 2008).

\section{Conclusões}

1. A salinidade foi elevada, mas, dentre as fontes de sais, a água de barragem promoveu maior salinização;

2. Independente da fonte o aumento do teor salino das águas inibem o crescimento do mamoeiro Havai, mas com maior expressão para o $\mathrm{NaCl}$;

3. As plantas foram mais sensíveis ao efeito dos sais na fase de crescimento do que na emergência;

4. A ordem dos efeitos das fontes de águas salinas foi: a) $\mathrm{Na}$ salinização do solo; água de barragem $>\mathrm{NaCl}>\mathrm{Na}_{2} \mathrm{SO}_{4}$; b) No crescimento e diâmetro do caule: $\mathrm{NaCl}>$ água de barragem $>\mathrm{Na}_{2} \mathrm{SO}_{4}$; c) $\mathrm{Na}$ biomassa radicular: $\mathrm{NaCl}>\mathrm{ASB}>\mathrm{Na}_{2} \mathrm{SO}_{4} ; \mathrm{Na}$ parte aérea: $\mathrm{NaCl}>\mathrm{Na}_{2} \mathrm{SO}_{4}>\mathrm{ASB}$.

5. A partir dos resultados expostos, constata-se que o nível de salinidade da água de irrigação mais adequado para o crescimento de mudas de mamoeiro Havai cv. Sunrise Solo é o de menor salinidade $(0,4$ $\mathrm{dS} \mathrm{m} \mathrm{m}^{-1}$ ).

\section{Referências}

ABREU, C. E. B.; PRISCO, J. T.; NOGUEIRA, A. R. C.; BEZERRA, M. A.; LACERDA, C. F.; GOMES-FILHO, E. Physiological and biochemical changes occurring in dwarf-cashew seedlings subjected to salt stress. Brazilian Journal Plant Physiology, Campinas, v. 20, n. 2, p. 105118, 2008.

ANUÁRIO BRASILEIRO DE FRUTICULTURA. Gazeta: Santa Cruz do Sul, RS. 2010, 129 p.

AYERS, R. S.; WESTCOT, D. W. Qualidade da água na agricultura. In: GHEYI, H. R.; MEDEIROS, J. L.; DAMASCENO, F. A. V. (Trad.). Campina Grande: Universidade Federal da Paraíba. 1999. 153 p. (Estudos FAO: Irrigação e Drenagem, 29 Revisado).

BRASIL. Ministério da Agricultura Reforma Agrária. Regras para análise de sementes. Brasília: SNDA/ DNPV/CLAV, 1992.365 p.

CAVALCANTE, L. F.; CARVALHO, S. S.; LIMA, E. M.; FEITOSA FILHO, J. C.; SILVA, D. A. Desenvolvimento inicial da gravioleira sob fontes e níveis de salinidade da água. Revista Brasileira de Fruticultura, Jaboticabal, v. 23, n. 2, p. 455-459, 2001.

CAVALCANTE, L. F.; CORDEIRO, J. C.; MESQUITA, E. F.; ARAÚJO, F. A. R.; DANTAS, T. A. G.; RAPOSO, R. W. C. Mamoeiro e a salinidade. In: CAVALCANTE, L. F.; LIMA, E. M. (Ed.). Algumas frutíferas tropicais e a salinidade. Jaboticabal: Funep, 2006. 148 p.

CAVALCANTE, L. F.; DANTAS, T. A. G.; ANDRADE, R.; SÁ, J. R.; MACÊDO, J. P. S.; GONDIM, S. C.; CAVALCANTE, Í. H. L. Resposta do maracujazeiroamarelo à salinidade da água sob diferentes formas de plantio. Revista Brasileira de Engenharia Agrícola e Ambiental, Campina Grande, v. 9, p. 314-317, 2005. Suplemento.

COSTA, E. G.; CARNEIRO, P. T.; SOARES, F. A. L.; FERNANDES, P. D.; GHEYI, H. R.; CAVALCANTE, L. F. Crescimento inicial do maracujazeiro amarelo sob diferentes tipos e níveis de salinidade da água de irrigação. Revista Brasileira Engenharia Agrícola e Ambiental, Campina Grande, v. 9, p. 242-247, 2005. Suplemento.

EL-HENDAWY, S. E.; HU, Y.; YAKOUT, G. M.; AWAD, A. M.; HAFIZ, S. E.; SCHIMIDHALTER, U. Evaluating salt tolerance of wheat genotypes using multiple parameters. Europ. J. Agronomy, Amsterdam, v. 22, n. 1, p. 243-253, 2005. 
FERREIRA, P. A. GARCIA, G. O.; SANTOS, D. B.; OLIVEIRA, F. G. Uso de água salina na agricultura. Workshop Uso e Reúso de Águas de Qualidade Inferior: Realidades e Perspectivas. Campina Grande: UFCG, 2005.

FERREIRA, R. G.; TAVORA, F. J. A. F.; HERNANDES, F. F. F. Distribuição da matéria seca e composição das raízes, caule e folhas de goiabeira submetida a estresse salino. Pesquisa Agropecuária Brasileira, Brasília, v. 36, n. 1, p. 79-88, 2001.

FERREIRA-SILVA S. L.; SILVEIRA, J. A. G.; VOIGT, E. L.; SOARES, L. S. P.; VIÉGAS, R. A. Changes in physiological indicators associated with salt tolerance in two contrasting cashew rootstocks. Brazilian Journal Plant Physiology, Campinas, v. 20, n. 1, p. 51-59, 2008.

FREIRE, J. O.; CAVALCANTE, L. F.; REBEQUI, A. M.; DIAS, T. J.; NUNES, J. C.; CAVALCANTE, I. H. L. Atributos qualitativos do maracujá amarelo produzido com água salina, biofertilizante e cobertura morta no solo. Revista Brasileira de Ciências Agrárias, Recife, v. 5, n. 1, p. 102-110, 2010.

GALVÃO, O. R.; ARAÚJO NETO, S. E.; SANTOS, F. C. B.; SILVA, S. S. Desempenho de mudas de mamoeiro cv. sunrise solo sob diferentes substratos orgânicos. Revista Caatinga, Mossoró, v. 20, n. 3, p.144-151, 2007.

GHEYI, H. R.; FERNANDES, P. D.; CAVALCANTE, L. F.; SANTOS, J. G. R.; SOARES, F. A. L. Bananeira e a salinidade. In: CAVALCANTE, L. F.; LIMA, E. M. (Ed.). Algumas frutiferas tropicais e a salinidade. Jaboticabal: Funep, 2006. 148 p.

HU, Y.; SCHIMIDHALTER, U. Limitation of salt stress to plant growth. In: HOCK, B.; ELSTNER, E. (Ed.). Plant toxicology. 4. ed. New York: Marcel Dekker Inc., 2004. p. 191-224.

LIMA, J. F.; PEIXOTO, C. P.; LEDO, C. A. S. Índices fisiológicos e crescimento inicial de mamoeiro (Carica papaya 1.) em casa de vegetação. Ciência e Agrotecnologia, Lavras, v. 31, n. 5, p. 1358-1363, 2007.

LIMA, K. L.; CAVALCANTE, L. F.; FEITOSA FILHO, J. C. Efeito de fontes e níveis de salinidade da água de irrigação sobre a germinação e o crescimento da pinheira. Engenharia Agrícola, Jaboticabal, v. 21, n. 2, p. 135-144, 2001.

MORAIS, D. L.; VIÉGAS, R. A.; SILVA, L. M. M.; LIMA JUNIOR, A. R.; COSTA, R. C. L.; ROCHA, I. M. A.; SILVEIRA, J. A. G. Acumulação de íons e metabolismo de $\mathrm{N}$ em cajueiro anão em meio salino.
Revista Brasileira de Engenharia Agrícola e Ambiental, Campina Grande, v. 11, n. 2, p. 125-133, 2007.

NASCIMENTO, J. A. M. Respostas do maracujazeiro amarelo em solo com biofertilizante bovino irrigado com água de baixa e alta salinidade. 2010. Dissertação de Mestrado (Manejo de Solo e Água) - Centro de Ciências Agrárias. Universidade Federal da Paraíba, Paraíba.

OLIVEIRA, J. R. P.; TRINDADE, A. V. Propagação e formação do pomar. In: TRINDADE, A. V. (Org.). Mamão, produção, aspectos técnicos. Cruz das Almas: Embrapa Mandioca e Fruticultura, 2000. p. 20-25.

PARIDA, A. K.; DAS, A. B. Salt tolerance and salinity effects on plants: a review. Ecotoxicology and Enviromental safety, USA, v. 60, n. 3, p. 324-349, 2005.

RICHARDS, L. A. Diagnóstico y rehabilitación de suelos salinos e y sodicos. México: Departamento de Agricultura do Los Estados Unidos de América. 5. ed. México: Limusa, 1954. 172 p. (Manual de Agricultura, $60)$.

SANTOS, E. C. dos. Efeito do cloreto de sódio na germinação e no desenvolvimento inicial do mamoeiro. 2000. Monografia (Graduação em Agronomia) - Escola Superior de Agricultura de Mossoró, Mossoró.

SAQIB, M.; AKHTAR, J.; QURESHI, R. H. Pot study on wheat growth in saline waterlogged compacted soil II. Root growth and leaf ionic relations. Soil and Tillage Research, Amsterdam, v. 77, n. 2, p. 179-187, 2004.

SHI, H. Z.; ZHU, J. K. Regulation of expression of the vacuolar $\mathrm{Na}^{+} / \mathrm{H}^{+}$antiporter gene AtNHX1 by salt stress and abscisic acid. Plant and Molecular Biology, Barcelona, v. 50, n. 3, p. 543-550, 2002.

TAIZ, L.; ZEIGER, E. Fisiologia vegetal. 3. ed. Porto Alegre: Artmed. 2006. 719 p.

TÁVORA, F. J. A. F.; PEREIRA, R. G.; HERNADEZ, F. F. F. Crescimento e relações hídricas em plantas de goiabeira submetidas a estresse salino com $\mathrm{NaCl}$. Revista Brasileira de Fruticultura, Jaboticabal, v. 23, n. 2, p. 441-446. 2001.

TESTER, M.; DAVENPORT, R. $\mathrm{Na}^{+}$tolerance and $\mathrm{Na}^{+}$ transport in higher plants. Annals of Botany, Oxford, v. 91, n. 5, p.503-527, 2003.

YAMANISHI, O. K.; FAGUNDES, G. R.; MACHADO FILHO, J. A.; VALONE, G. V. Efeito de diferentes substratos e duas formas de adubação na produção de mudas de mamoeiro. Revista Brasileira de Fruticultura, Jaboticabal, v. 26, n. 2, p. 276-279, 2004. 
